\title{
EDITORIAL
}

\section{Journal OF Micro/NANO LithogRAPHY, MEMS, AND MOEMS}

$\mathrm{JM}^{3}$ has stood for the Journal of Microlithography, Microfabrication, and Microsystems since its inauguration in 2002. It will be changed to stand for the Journal of Micro/Nano Lithography, MEMS, and MOEMS.

We have been asking ourselves whether the name will stay micro forever while the imaging and fabrication technologies have marched below $100 \mathrm{~nm}$ with overlay requirement in teens of nanometers and $C D$ control in single digits of nanometers. There are $\mathrm{JM}^{3}$ articles that advocate wavelength in the teens. Roadmaps for 32-nm and 22-nm half pitches are becoming household words. In these cases, overlay and CD control are in single digits of nanometers. Microlithography deservingly can be renamed nanolithography.

However, the word microlithography is deeply imbedded in us, microlithographers. We have been so very proud to be associated with the name. Also, the micrometer dimension is still very prosperous. Since human beings have not shrunken, many microdevices need not shrink any further. Therefore, we will cover both microlithography and nanolithography and rename microlithography into micro/nano lithography.

In addition to changing the word "microlithography," we will also change "microfabrication and microsystems" to "MEMS and MOEMS." This does not mean that we will not cover the microfabrication and microsystem fields, but rather that we are emphasizing our linkage with MEMS and MOEMS. The synergy in these five M-fields is indeed very strong. Micro/nano lithography, MEMS, and MOEMS inevitably encompass microfabrication and microsystems. The same is true with microfabrication and microsystems encompassing the other three fields. We use the new name to identify the journal better with our authors and readers. Notice that it is now easier to pronounce the new name.

Changing the name of a journal is not a small matter. All appearances on the printed journal, digital library, website, signs, banners, subscription forms, and even the record at the post office have to be changed. It will take many months to complete the name change.

\section{New Senior Editor in MOEMS}

I would like to welcome Dr. M. Edward Motamedi who recently become a senior editor in MOEMS for $\mathrm{JM}^{3}$. Dr. Motamedi was the guest editor of the recent $\mathrm{JM}^{3}$ special section on MOEMS and has been an associate editor of $\mathrm{JM}^{3}$ since its inception. He has chaired/edited II technical proceedings and is the author/editor of the book MOEMS: Micro-Opto-Electro-Mechanical Systems. Dr. Motamedi is the founder and CTO at Revoltech, Inc. He has been associated with Rockwell Science Center for more than 18 years and has founded Asentec Corp. and MOEMS Tech. Inc., intermixed with his career at Rockwell. Dr. Motamedi is highly reputable in the field of MOEMS. We look forward to his escalating contribution to $\mathrm{JM}^{3}$, especially in the field of MOEMS in light of the new name of $\mathrm{JM}^{3}$.

Happy reading!

\section{Burn J. Lin, Editor-in-Chief}

